\title{
Effect of eggshell/N,N-dimethylformamide (DMF) mixing ratios on the sonochemical production of $\mathrm{CaCO}_{3}$ nanoparticles
}

\author{
Kenneth Mensah ${ }^{1 *}$ (D) Ayda Mostafa Abdelmageed ${ }^{2}$ and Hassan Shokry ${ }^{1,3}$
}

\author{
* Correspondence: kenneth. \\ mensah@ejust.edu.eg \\ ${ }^{1}$ Environmental Engineering \\ Department, Egypt-Japan University \\ of Science and Technology, New \\ Borg El Arab City, Alexandria, Egypt \\ Full list of author information is \\ available at the end of the article
}

\begin{abstract}
Bio- $\mathrm{CaCO}_{3}$ nanoparticles have several applications and have attracted significant attention in current research. N,N-dimethylformamide (DMF) has been proven to be an effective non-volatile solvent for synthesizing bio- $\mathrm{CaCO}_{3}$ nanomaterials from eggshell. However, the optimum ratio of eggshell and DMF need to be specified to achieve maximum nano- $\mathrm{CaCO}_{3}$ production for large-scale purposes. Thus, this work investigated the effect of eggshell/DMF mixing ratios on the production of $\mathrm{CaCO}_{3}$ nanoparticles from the chicken eggshell. The nano- $\mathrm{CaCO}_{3}$ were synthesized via dry milling and then sonication at a frequency of $40 \mathrm{kHz}$ for $6 \mathrm{~h}$ in the presence of DMF. The eggshell mass was varied from 0.5 to $20 \mathrm{~g}$ per $100 \mathrm{~mL}$ of DMF. The synthesized $\mathrm{CaCO}_{3}$ materials were characterized using SEM, TEM, EDX, XRD, and BET surface analysis. The eggshell/DMF ratio was optimized to maximize the production of $\mathrm{CaCO}_{3}$ nanoparticles, and its effect on the size, crystallinity, surface area, and porosity of the $\mathrm{CaCO}_{3}$ particles were discussed. Increasing eggshell/DMF ratio decreased the sonication efficiency with increasing crystallite and particle size. The specific surface area of the synthesized $\mathrm{CaCO}_{3}$ particles decreased with increasing eggshell/DMF ratio. $1 \mathrm{~g} / 100 \mathrm{~mL}$ was the optimum or highest ratio to obtain $100 \%$ nano- $\mathrm{CaCO}_{3}$. At $1 \mathrm{~g} / 100 \mathrm{~mL}$ ratio, the bio- $\mathrm{CaCO}_{3}$ contained a crystallite size of $23.08 \mathrm{~nm}$, particle size between 5 and $30 \mathrm{~nm}$ and surface area of $47.44 \mathrm{~m}^{2} \mathrm{~g}^{-1}$.
\end{abstract}

Keywords: Nanoparticles, Bio- $\mathrm{CaCO}_{3}$, Recycling, Eggshell, Ultrasonic irradiation

\section{Introduction}

Current waste management strategies involve minimizing waste, as well as collection and storage/treatment [1, 2]. However, waste such as biomass generated from agricultural and domestic activities is inevitable [3]. These biomasses like eggshells are generated daily in enormous quantities since their main products are life-dependent: source of food $[4,5]$. Although agro-biomass is biodegradable in the natural environment, the biomass contains vital compounds or elements that have many uses [6]. For instance, carbon found in biomass can serve as a precursor for producing fuels, gas, adsorbents, and several others [5, 7-10]. Hence, waste biomasses are valuable materials, and the

(C) The Author(s). 2022 Open Access This article is licensed under a Creative Commons Attribution 4.0 International License, which permits use, sharing, adaptation, distribution and reproduction in any medium or format, as long as you give appropriate credit to the original author(s) and the source, provide a link to the Creative Commons licence, and indicate if changes were made. The images or other third party material in this article are included in the article's Creative Commons licence, unless indicated otherwise in a credit line to the material. If material is not included in the article's Creative Commons licence and your intended use is not permitted by statutory regulation or exceeds the permitted use, you will need to obtain permission directly from the copyright holder. To view a copy of this licence, visit http://creativecommons.org/licenses/by/4.0/. The Creative Commons Public Domain Dedication waiver (http://creativecommons.org/publicdomain/zero/1.0/) applies to the data made available in this article, unless otherwise stated in a credit line to the data. 
valorization of such waste is sustainable, economical, and generally eco-friendly [11, 12]. Moreover, recycling waste offers a more cost-effective approach to managing waste and preventing environmental pollution [13].

Eggshells are industrial and household byproducts; thus, they are abundant and available at a low cost. The global egg production is around 77 million tonnes, resulting in over a million tonnes of eggshell biomass created as waste each year [14, 15]. However, the majority of eggshells are disposed in landfills [5]. Meanwhile, eggshell is a biodegradable material with extraordinary properties such as a unique natural porous structure and a high calcium carbonate (bio- $\mathrm{CaCO}_{3}$ ) concentration $(95 \mathrm{wt} \%$ ) in the form of calcite [16, 17]. Thus, eggshells can be used in various applications, including as a biosorbent for environmental treatment, where it has a strong affinity for heavy metal ions and dyes $[18,19]$. The calcite in eggshell can also be used: in the production of biocompatible ceramic materials, as an abrasive ingredient in toothpaste, coating pigments for ink-jet printing paper, as bio-filler to improve the properties of polymer nanocomposites, to improve the mechanical behavior and tensile properties of polypropylene composites, controlled epoxy resin composite, and improve the thermal stability and glass transition temperature of normal corn starch foams [12, 17, 20, 21].

On the other hand, nanotechnology involves the conversion of bulk materials to nanometric size $(<100 \mathrm{~nm})$ [22, 23]. Nanotechnology introduces unique characteristics into materials and makes them widely applicable as catalysts, structural components, information storage, electronics, and sensors [24-28]. Hence, nanomaterials have been the focus of current research $[28,29]$. Studies have shown that the conversion of eggshells into nanometric size presents significant advantages over bulk or micrometer-sized eggshells $[17,30]$. Nanometric eggshell has a relatively high surface area and uniform pore distribution. Therefore, nano-eggshell is used as a more efficient adsorbent for dyes and metals in solution and additive for plastics and ceramic composites to improve their properties [17]. Other studies have shown that nanometric eggshells can be more effectively deposited on the biochar matrix to improve the adsorption capabilities [18].

Meanwhile, several top-bottom methods can be used to synthesize nanomaterials [31]. High-energy ball milling is the most widely used method in producing nanomaterials because ball milling is simple, applicable for numerous materials, and can be advanced quickly for commercial production [32]. However, the comminution of particles from micrometer to nanometer scale by milling requires much energy and is costly [32]. Further drawbacks of milling include particle agglomeration and nanomaterial contamination [32]. Consequently, other methods such as ultrasonic irradiation have been employed as an effective alternative for synthesizing nanomaterials with remarkable properties [17].

Sonochemistry is an acoustic cavitation process that involves the creation, growth, and implosive collapse of bubbles in a liquid medium [33]. This result in extreme conditions such as high temperatures (>5000 K), high pressure (>20 MPa), and high cooling rate $\left(>107 \mathrm{~K} \mathrm{~s}^{-1}\right)$ [34]. These extreme conditions introduce many unique properties in the irradiated solution, affecting the size reduction [34]. Sonication is a suitable method for reducing the particle size of many inorganic materials while preserving the crystalline structure [35]. A study by Hassan et al. (2013) investigated the preparation of bio- $\mathrm{CaCO}_{3}$ nanoparticles from eggshell using wet ball milling with polypropylene glycol. The ball-milled eggshell particles were then irradiated a sonochemical process in 
the presence of N,N-dimethylformamide (DMF), decahydronaphthalene (Decalin), and tetrahydrofuran (THF). DMF was reported as the most effective solvent [17]. Low volatile solvents like DMF have relatively low vapor pressures and are effective solvents for synthesizing biobased nanomaterials via the sonochemical process [17, 35].

Nevertheless, a crucial aspect of the nano- $\mathrm{CaCO}_{3}$ preparation via the sonochemical process which includes optimizing the mixing ratios between the eggshell powder and solvent has not been discussed [36-39]. Such study is vital to the large-scale production of the bio- $\mathrm{CaCO}_{3}$ nanoparticles from this process. This can specify the maximum eggshell/DMF ratio required to produce high yield eggshell nanoparticles via the sonochemical process. Moreover, studies have shown that the efficiency of sonochemical processes is critically dependent on the solid/solvent ratio [40].

This present study investigates the effect of eggshell/DMF mixing ratios on the sonochemical production of $\mathrm{CaCO}_{3}$ nanoparticles for large-scale applications. This is the first study that examines the eggshell/DMF mixing ratios and optimizes the ratios to maximize $\mathrm{CaCO}_{3}$ nanoparticle production. This work further discusses the effect of the mixing ratios on the size, crystallinity, and porosity of the $\mathrm{CaCO}_{3}$ nanoparticles.

\section{Materials and experimental method}

\section{Materials and reagents}

Chicken eggshells were collected from a local restaurant in Borg El Arab, Egypt. Acetone (99.8\%) was purchased from Fisher Scientific in the UK. N,N-dimethylformamide (99.8\% DMF) was purchased from Sigma-Aldrich in Germany. Ethanol (70\%) was procured from Brand Chemicals in Egypt.

\section{Synthesis of $\mathrm{CaCO}_{3}$ nanoparticles}

A modified method of synthesizing $\mathrm{CaCO}_{3}$ nanoparticles from the chicken eggshell powder was used, as illustrated in Fig. $1 \mathrm{a}-\mathrm{f}[17,18]$. The eggshells were thoroughly washed with demineralized water and dried overnight in a $110{ }^{\circ} \mathrm{C}$ oven (Fig. 1a). The dry eggshells were pulverized for 5 min using a blender to obtain an eggshell powder. The fine eggshell powder was then soaked in acetone and stirred for $2 \mathrm{~h}$. The shells were then dried in an oven at $60{ }^{\circ} \mathrm{C}$ for $2 \mathrm{~h}$. The dried eggshell powder was ground to

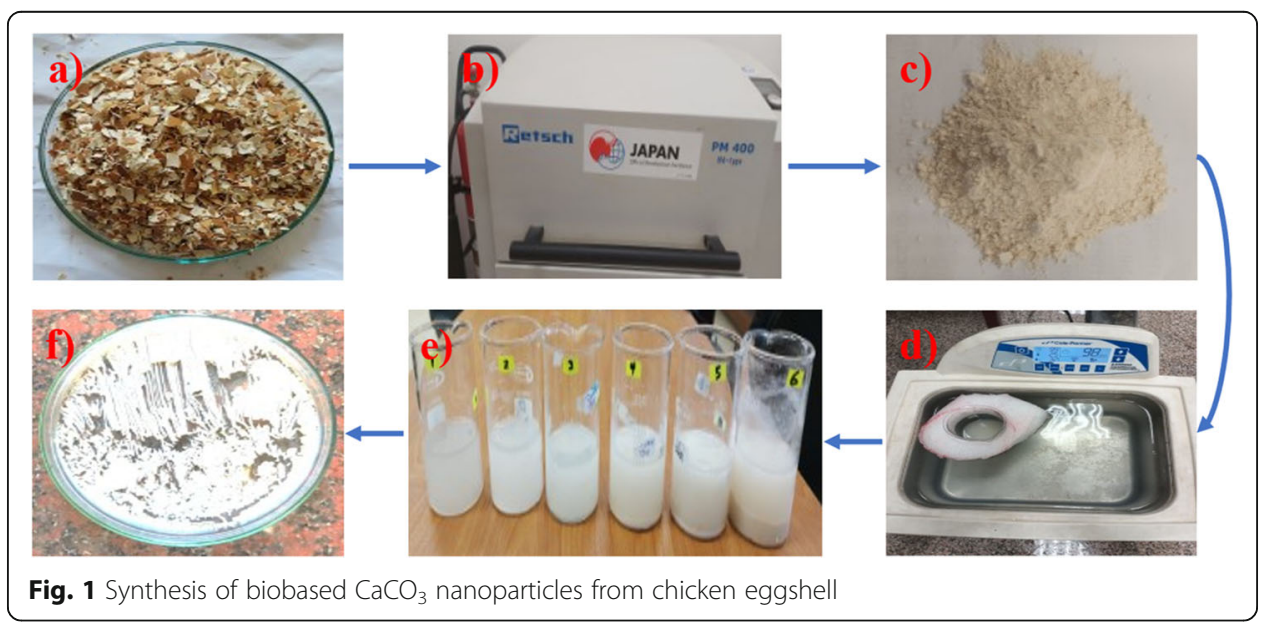


below $106 \mu \mathrm{m}$ sizes using a Retsch PM 400 planetary mill with $1 \mathrm{~mm}$ diameter ceramic balls at a ratio of 1:1 for $5 \mathrm{~h}$ (Fig. 1b). An amount of the eggshell powder (Fig. 1c) was irradiated in the presence of a fixed $100 \mathrm{~mL}$ DMF in a glass beaker at a frequency of 40 $\mathrm{kHz}$ using Cole-Parmer digital ultrasonicator for $6 \mathrm{~h}$ (Fig. 1c). The suspensions were manually stirred regularly to reduce particle settling. After the sonochemical reaction, the particles were collected and washed repeatedly with ethanol (Fig. 1e). The final product was centrifuged at $6000 \mathrm{rpm}$ for $30 \mathrm{~min}$ using Hettich EBA 20 centrifuge to separate the eggshell particles from the solvents. Eggshell particles were then dried under vacuum for $24 \mathrm{~h}$ (Fig. 1f) and stored in a vacuum desiccator. The samples were labelled ES-1, ES-2, ES-3, ES-4, ES-5, and ES-6, corresponding to an eggshell powder mass of $0.5,1,2,5,10$, and $20 \mathrm{~g}$, respectively.

\section{Characterization techniques for the $\mathrm{CaCO}_{3}$ nanoparticles}

Surface morphological analysis and size measurement of the prepared $\mathrm{CaCO}_{3}$ samples was conducted using a scanning electron microscope (SEM) (JEOL, JSM-6010LV, Japan). Higher-resolution micrographs of the morphology, nano-size particle measurement, and elemental composition of the samples were determined using a transmission electron microscope (TEM) equipped with energy dispersion X-ray spectroscopy (EDX) (JEOL, JEM-2100F, Japan). Bruker D2 Phaser was used to generate X-ray diffraction (XRD) crystallographic information of the $\mathrm{CaCO}_{3}$ samples. Nitrogen gas $\left(\mathrm{N}_{2}\right)$ adsorption-desorption test and the Barrett, Joyner, and Halenda (BJH) analysis were conducted to examine the surface texture and pore size distributions. The BrunauerEmmett-Teller (BET) surface area, mean pore size and total pore volume of the char products were analyzed with Microtrac MRB Belsorp Mini X, Japan.

\section{Results and discussion}

The XRD patterns of the prepared bio- $\mathrm{CaCO}_{3}$ (Fig. 2) show peaks at $2 \theta^{\circ}$ of approximately $23^{\circ}, 29^{\circ}, 36^{\circ}, 39^{\circ} .43^{\circ}, 47^{\circ}, 48^{\circ}, 57^{\circ}, 61^{\circ}$, and $65^{\circ}$ corresponding to the (012), (104), (110), (113), (202), (016), (018), (122), (224), and (036) diffraction planes of calcite phase of $\mathrm{CaCO}_{3}$ (JCPDS card No. 47-1743) [17, 21]. The presence of sharp peaks indicates highly crystalline $\mathrm{CaCO}_{3}$ in all samples. The characteristic calcite diffraction peaks present in all samples are positioned at approximately the same angles indicating that the sonochemical irradiation caused no structural changes to the chemical composition of the sonicated samples. Moreover, calcite is the most stable polymorph of calcium carbonate and will not easily undergo any structural changes [21, 41, 42]. The EDX spectra (Fig. 3) confirm peaks of calcium (Ca), carbon (C), and oxygen (O), confirming the presence of $\mathrm{CaCO}_{3}$ with no impurities in all prepared bio- $\mathrm{CaCO}_{3}$.

OriginPro 9.8 software was used to estimate the full width at half maximum (FWHM) for all the bio- $\mathrm{CaCO}_{3}$ samples by fitting the Gaussian model on the most intense (104) peak at $2 \theta^{\circ}$ of $\sim 29^{\circ}$. The obtained FWHM values were used to calculate the crystallite size of the prepared bio- $\mathrm{CaCO}_{3}$ using the conventional Scherrer Equation at an X-ray wavelength of $0.154 \mathrm{~nm}$ and shape factor of 0.94 . The FWHM value of the (104) peak of the bio- $\mathrm{CaCO}_{3}$ particles decreased with the increasing ratio of eggshell/DMF with a corresponding increase in crystallite size (Table 1). This indicates that the smaller sizes of bio- $\mathrm{CaCO}_{3}$ particles are achievable at lower eggshell/DMF ratios. Studies have 


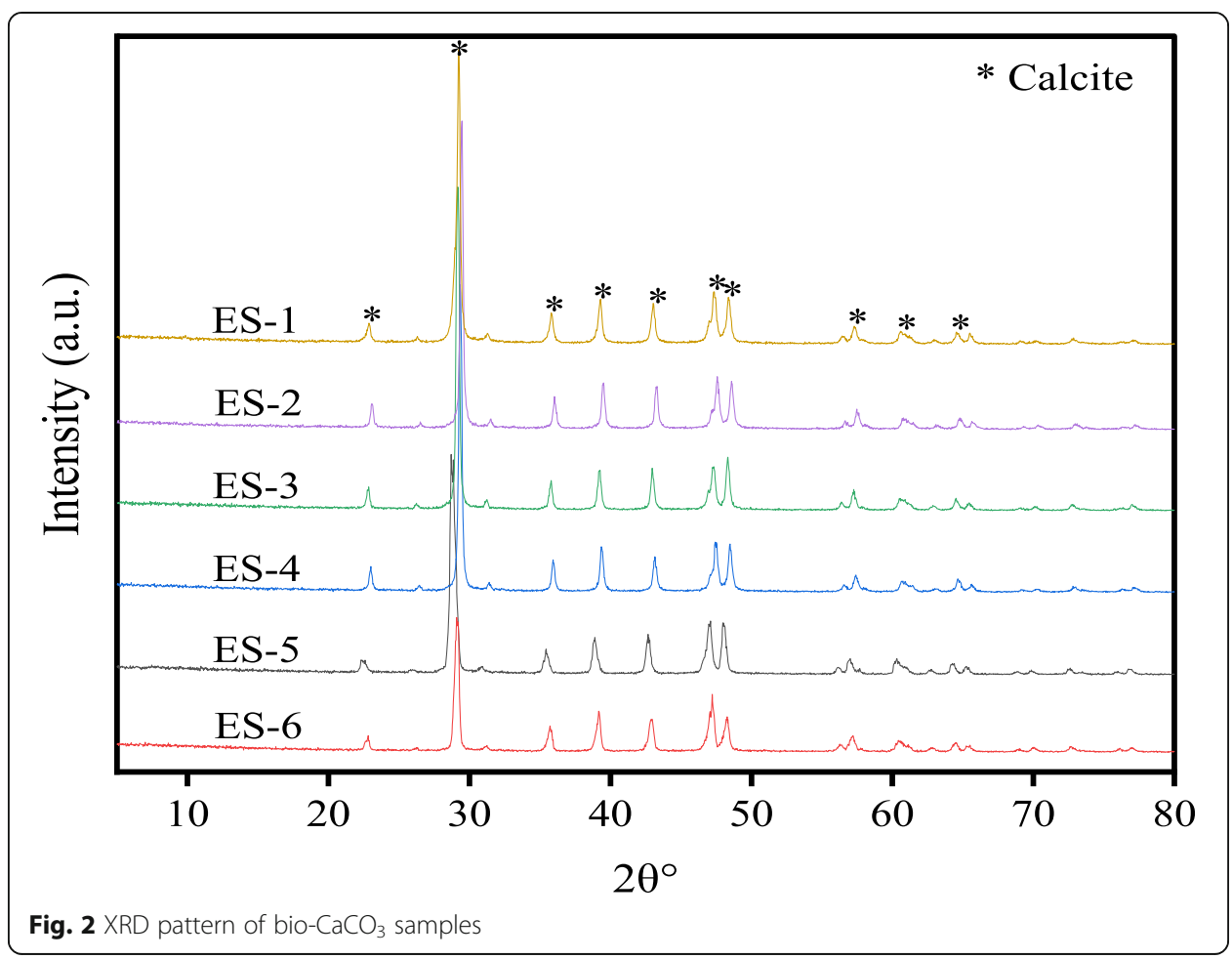

shown that solid particles tend to aggregate quickly in their suspensions when the solids mass increases [10]. Consequently, increasing $\mathrm{CaCO}_{3}$ particles aggregation with increasing eggshell mass caused the eggshell particles to settle quickly, impeding sonochemical process efficiency at higher eggshell concentrations [40, 43]. Moreover, the 1 transfer principle states that the increasing concentration gradient between the substance and the solvent is the driving factor for mass transfer [40]. Hence, increasing the eggshell mass causes rapid saturation of the DMF solvent, which reduces the efficiency of solids dispersion and accordingly decreases the sonochemical process efficiency [40, 43]. Contrarily, larger volume of solvent enhances the solvent extraction capability, preventing early saturation and enabling a higher production of nano- $\mathrm{CaCO}_{3}$ [40]. The crystallite sizes of ES-1 and ES-2 (18.07 and 23.08 respectively) are close to the crystalline size of nano- $\mathrm{CaCO} 3$ particles that were synthesized through the precipitation of dissolved $\mathrm{Ca}\left(\mathrm{NO}_{3}\right) 2 \cdot 4 \mathrm{H}_{2} \mathrm{O}$ [44]. This indicates a possible production of nano- $\mathrm{CaCO}_{3}$ particles from ES-1 and ES-2.

SEM micrographs of the bio- $\mathrm{CaCO}_{3}$ show clusters and agglomerations of calcite particles with irregular sizes and shapes (Fig. 4). Several fragmented bio- $\mathrm{CaCO}_{3}$ particles were observed in ES-1 (Fig. 4a) and ES-2 (Fig. 4b), illustrating the impact of sono-irradiation in breaking down the eggshell particles. However, the particle size of the prepared bio- $\mathrm{CaCO}_{3}$ increased with increasing eggshell/DMF ratio. From Fig. 4c (ES-3), Fig. 4d (ES-4), Fig. 4e (ES-5), and Fig. 4f (ES-6), a blend of fragmented and larger lumps of bio- $\mathrm{CaCO}_{3}$ are observed with an increasing amount of larger lumps with higher eggshell/DMF ratio. This confirms the results from the XRD analysis illustrating the effect of eggshell/DMF mixing ratio on the sonochemical production of bio- $\mathrm{CaCO}_{3}$.

TEM analysis provided further detailed imagery of the morphology (Fig. 5) and measurements of the particle sizes of the synthesized bio- $\mathrm{CaCO}_{3}$ (Table 2). The TEM 

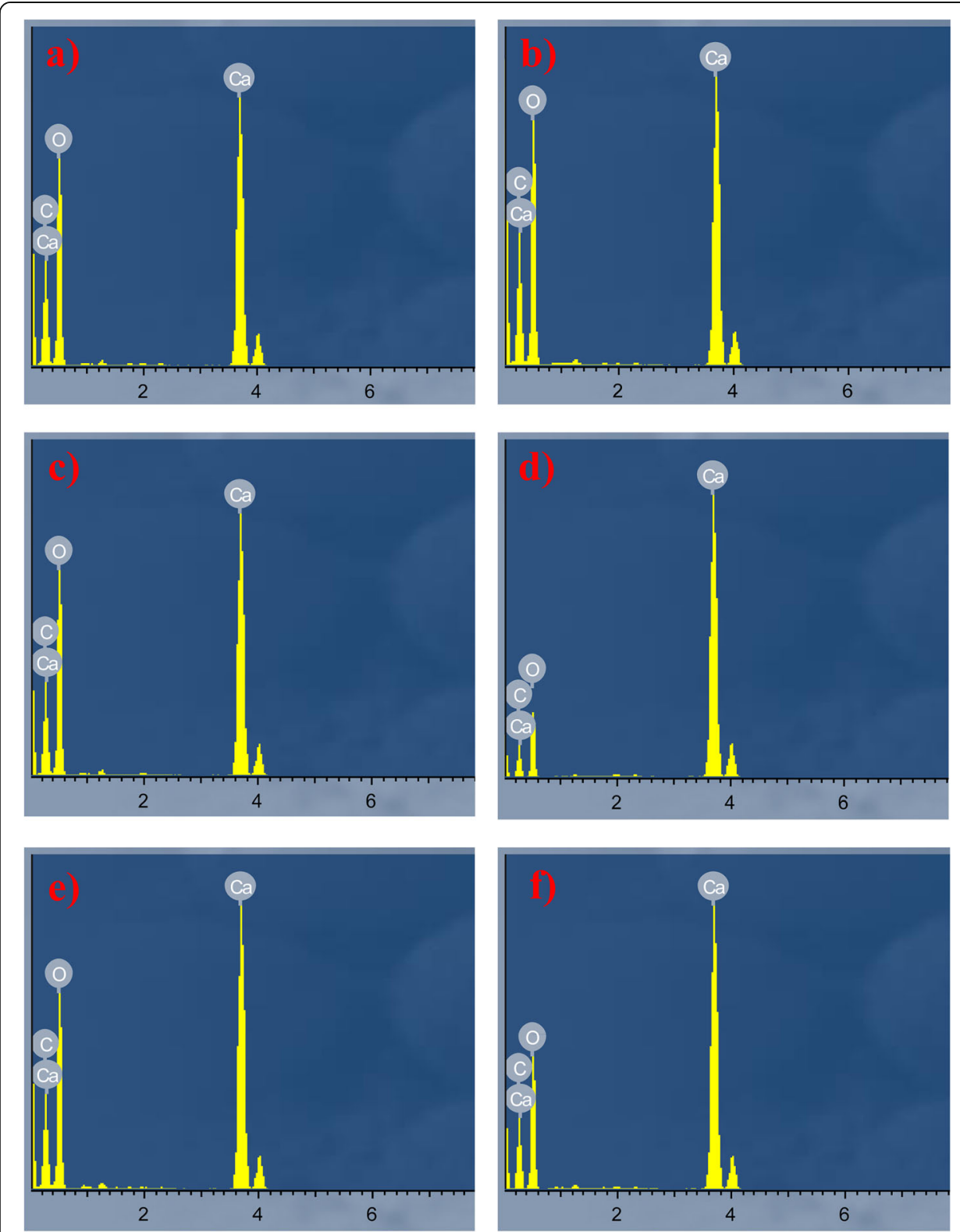

Fig. 3 EDX spectra of a ES-1, b ES-2, c ES-3, d ES-4, e ES-5, and f ES-6

Table 1 Crystallite size of bio- $\mathrm{CaCO}_{3}$

\begin{tabular}{lll}
\hline Sample & $\mathbf{F W H M}$ at $\mathbf{2}^{\circ} \mathbf{2}^{\circ}$ & Crystallite sze at $\mathbf{2 9}^{\circ} \mathbf{2 \boldsymbol { \theta } ^ { \circ } \mathbf { ( n m } )}$ \\
\hline ES-1 & 0.474 & 18.07 \\
ES-2 & 0.371 & 23.08 \\
ES-3 & 0.349 & 24.54 \\
ES-4 & 0.277 & 30.92 \\
ES-5 & 0.275 & 31.14 \\
ES-6 & 0.246 & 34.81 \\
\hline
\end{tabular}



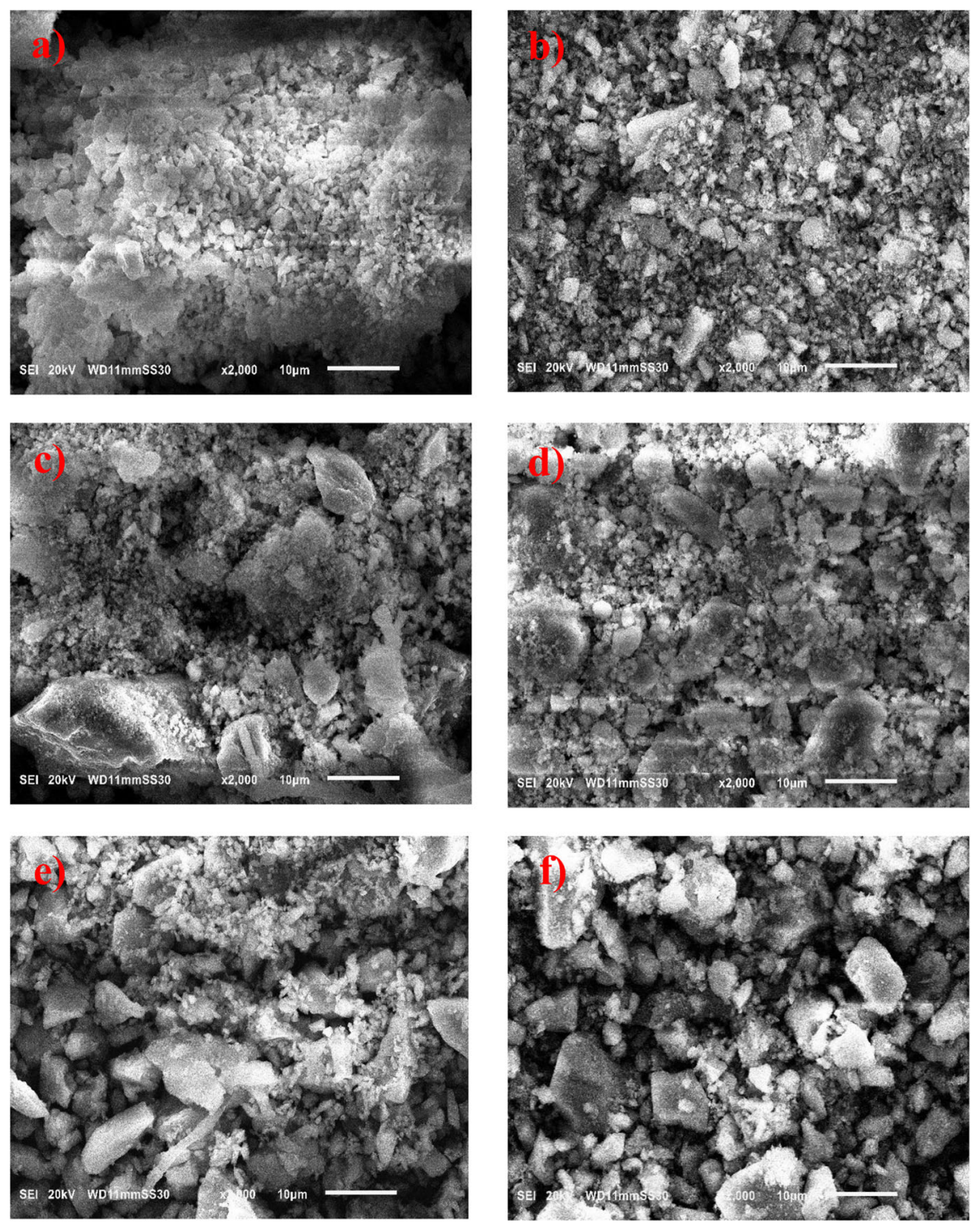

Fig. 4 SEM micrographs of a ES-1, b ES-2, $\mathbf{c}$ ES-3, d ES-4, e ES-5, and $\mathbf{f}$ ES-6

micrographs show the presence of $\mathrm{CaCO}_{3}$ platelets in all samples with shadows depicting agglomerations (Fig. 5). ES-1 (Fig. 5a) and ES-2 (Fig. 5b) contain irregular shapes of $\mathrm{CaCO}_{3}$ nano-platelets $(<100 \mathrm{~nm}$ ). However, ES-3 (Fig. 5c) contains similar irregular shapes of both nano and micro sizes. Meanwhile, ES-4. (Fig. 5d), ES-5 (Fig. 5e), and ES6 (Fig. 5f) contain a blend of nanometric and micro-size $\mathrm{CaCO}_{3}$ platelets with an increasing amount of micro-size $\mathrm{CaCO}_{3}$ particles as the eggshell concentration increases. Thus, $1 \mathrm{~g} / 100 \mathrm{~mL}$ (ES-2) is the maximum eggshell/DMF ratio to produce $100 \% \mathrm{CaCO}_{3}$ nanoparticles (less than $100 \mathrm{~nm}$ sizes).

The $\mathrm{N}_{2}$ adsorption and desorption isotherm curves of the bio- $\mathrm{CaCO}_{3}$ samples show increasing $\mathrm{N}_{2}$ sorption at high relative pressures as shown in Fig. 6a, which is characteristic of type-III isotherm according to the International Union of Pure and Applied Chemistry (IUPAC) classification [45]. This describes a mesoporous texture of all prepared bio- $\mathrm{CaCO}_{3}$ [46]. Meanwhile, for an equal volume of a specific material, the samples with smaller sizes have relatively high specific surface 

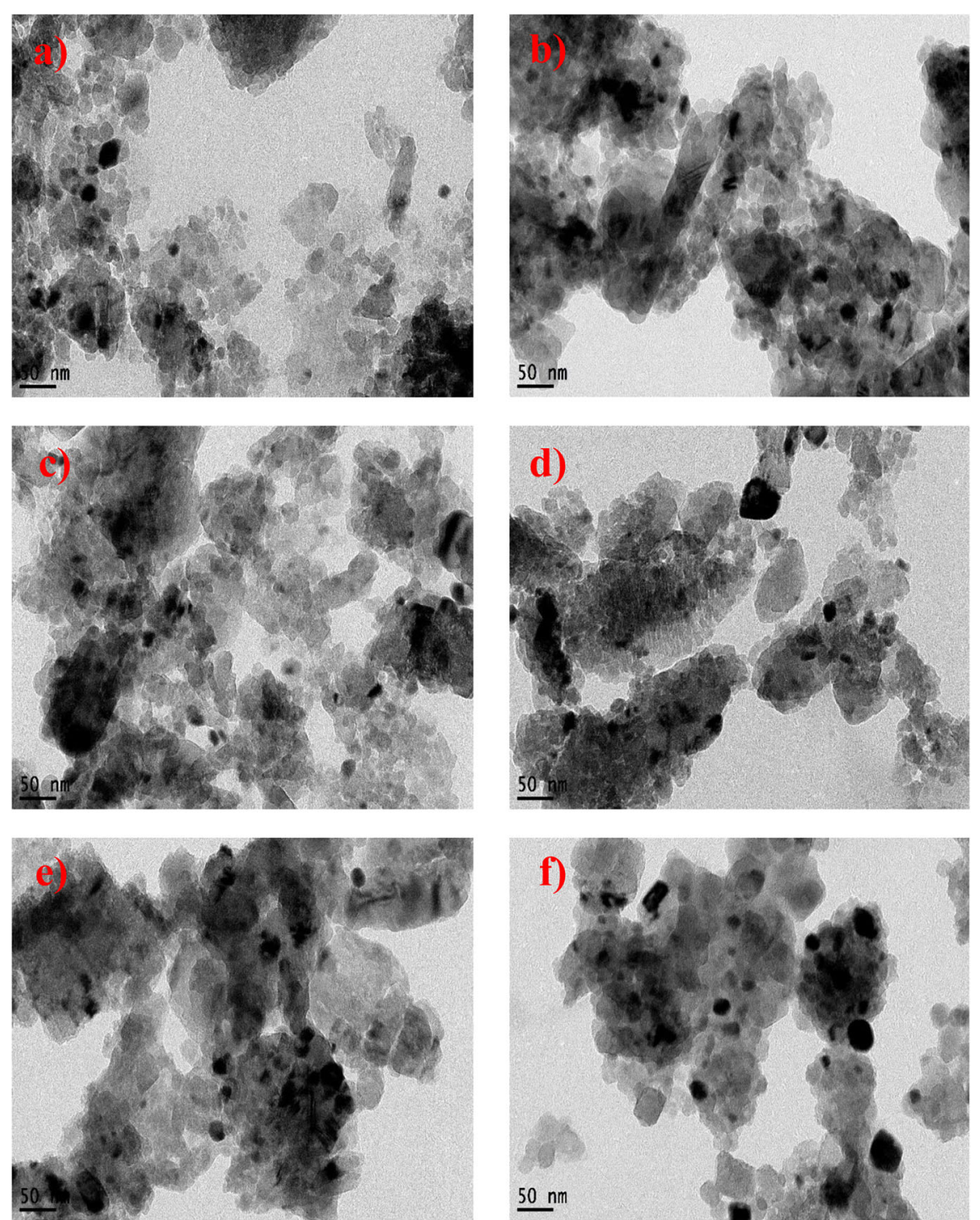

Fig. 5 TEM micrographs of a ES-1, b ES-2, c ES-3, d ES-4, e ES-5, and $\mathbf{f} E S-6$

area $[43,47,48]$. Accordingly, the $\mathrm{N}_{2}$ adsorption capacity increased with decreasing eggshell concentration depicting a relatively high surface of $\mathrm{CaCO}_{3}$ prepared from lower eggshell/DMF ratios (ES-1 > ES-6). This result confirms the production of smaller bio- $\mathrm{CaCO}_{3}$ particles with decreasing eggshell concentrations due to the subsequent improvement in the sonochemical process (slow saturation, lower

Table 2 Particle size and morphology of bio- $\mathrm{CaCO}_{3}$

\begin{tabular}{lll}
\hline Sample & Particle size range $(\mathbf{n m})$ & Morpholgy \\
\hline ES-1 & $5-20$ & Irregular-shaped platelets \\
ES-2 & $5-30$ & Irregular-shaped platelets \\
ES-3 & $10^{-4} \times 10^{4}$ & Irregular -shaped platelets \\
ES-4 & $10^{-7} \times 10^{4}$ & Blend of irregular and few rectangular platelets \\
ES-5 & $15-10^{5}$ & Blend of irregular and rectangular platelets \\
ES-6 & $20-10^{5}$ & Predominantly rectangular platelets \\
\hline
\end{tabular}



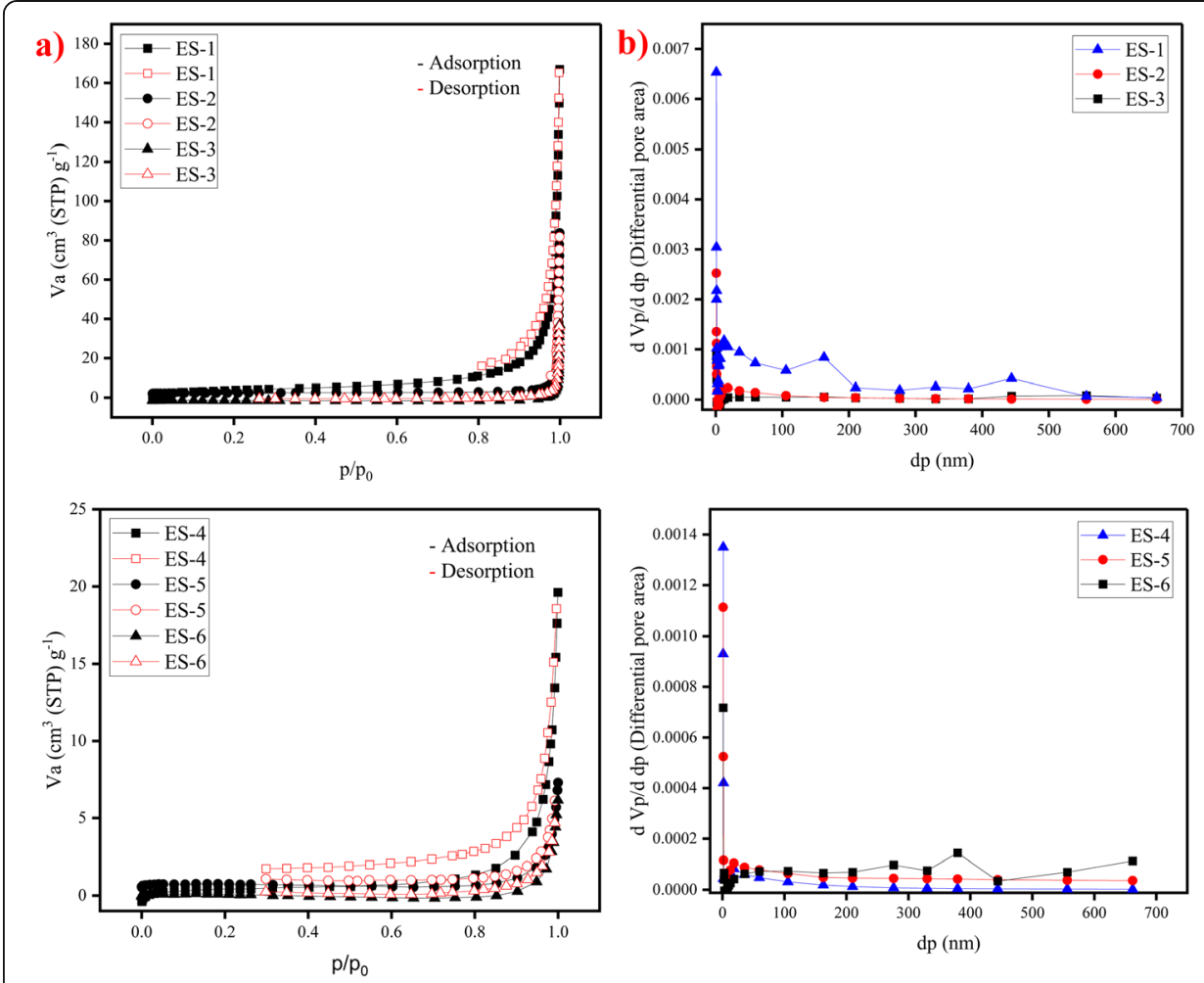

Fig. 6 a $\mathrm{N}_{2}$ adsorption-desorption isotherms and $\mathbf{b}$ pore distribution of bio- $\mathrm{CaCO}_{3}$ samples

tendency of particle agglomeration, and slower rate settling at lower eggshell concentration) at lower eggshell/DMF ratio. On the other hand, all the prepared bio- $\mathrm{CaCO}_{3}$ samples have broadly distributed pores ranging from 10 to $>100 \mathrm{~nm}$ (Fig. 6b). This shows that the sonochemical process had less impact on the porosity of the prepared bio- $\mathrm{CaCO}_{3}$. The BET surface area, average pore diameter and total pore volume of the prepared bio- $\mathrm{CaCO}_{3}$ are summarized in Table 3.

\section{Conclusion}

This work studied the effect of eggshell/DMF mixing ratio (0.5 to $20 \mathrm{~g}$ eggshell powder per $100 \mathrm{~mL}$ of DMF) on the sonochemical production of bio- $\mathrm{CaCO}_{3}$ nanoparticles. The size of the prepared bio- $\mathrm{CaCO}_{3}$ platelets increased with increasing eggshell/DMF ratio due to particle agglomeration, solvent saturation and rapid settling. The eggshell/DMF ratio was optimized to achieve maximum production of

Table 3 Textural properties of bio- $\mathrm{CaCO}_{3}$

\begin{tabular}{llll}
\hline Sample & BET surface area $\left(\mathbf{m}^{\mathbf{2}} \mathbf{g}^{\mathbf{- 1}}\right)$ & Total pore volume $\left(\mathbf{c m}^{\mathbf{3}} \mathbf{g}^{\mathbf{- 1}}\right)$ & Mean pore diameter $(\mathbf{n m})$ \\
\hline ES-1 & 52.62 & 0.181 & 39.30 \\
ES-2 & 47.44 & 0.179 & 41.22 \\
ES-3 & 42.38 & 0.164 & 35.27 \\
ES-4 & 27.39 & 0.159 & 36.01 \\
ES-5 & 14.43 & 0.154 & 48.08 \\
ES-6 & 13.25 & 0.142 & 39.35 \\
\hline
\end{tabular}


$100 \%$ nano- $\mathrm{CaCO}_{3}$ at ES-2 (1 g/100 mL eggshell/DMF ratio) and a sonication frequency of $40 \mathrm{kHz}$ for $6 \mathrm{~h}$. The prepared nano- $\mathrm{CaCO}_{3}$ from $\mathrm{ES}-2$ has a crystallite size of $23.08 \mathrm{~nm}$ and particle sizes between 5 and $30 \mathrm{~nm}$. The surface area of the prepared bio- $\mathrm{CaCO}_{3}$ decreased with increasing eggshell/DMF ratio due to the presence of large and lumpy $\mathrm{CaCO}_{3}$ fragments that remained at higher eggshell/DMF ratios ( $\geq 2 \mathrm{~g} / 100 \mathrm{~mL})$. At ES-2 (1 g/100 $\mathrm{mL}$ eggshell/DMF ratio), the BET surface area, pore volume and average pore diameter of the prepared nano- $\mathrm{CaCO}_{3}$ were $47.44 \mathrm{~m}^{2} \mathrm{~g}^{-1}, 0.179 \mathrm{~cm}^{3} \mathrm{~g}^{-1}$, and $41.22 \mathrm{~nm}$, respectively. The prepared bio- $\mathrm{CaCO}_{3}$ nanoparticles can be used in large-scale applications such as adsorption, polymer composites, and catalyst.

\section{Abbreviations}

ES: Eggshell; DMF: N,N-dimethylformamide; $\mathrm{CaCO}_{3}$ : Calcium carbonate; SEM: Scanning electron microscope; TEM: Transmission electron microscope; EDX: Energy dispersion X-ray spectroscopy; XRD: X-ray diffraction; BET: Brunauer-Emmett-Teller; BJH: Barrett, Joyner, and Halenda; $\mathrm{N}_{2}$ : Nitrogen gas; Ca: Calcium; C: Carbon; O: Oxygen; FWHM: Full width at half maximum; IUPAC: International Union of Pure and Applied Chemistry

\section{Acknowledgements}

Not applicable.

\section{Authors' contributions}

KM conceptualization, visualization, methodology-experimental work, formal analysis, writing_original draft; writing — review and editing; AMA: conceptualization, methodology_experimental work, writing —review and editing; HS: supervision, writing-review and editing. All authors read and approved the final manuscript.

\section{Funding}

The research received no specific grant from any funding agency in the public, commercial, or non-profit sectors.

\section{Availability of data and materials}

All data generated or analyzed during this study are included in this published article [and its supplementary information files].

\section{Declarations}

\section{Competing interests}

The authors declare that they have no competing interests.

\section{Author details}

${ }^{1}$ Environmental Engineering Department, Egypt-Japan University of Science and Technology, New Borg El Arab City, Alexandria, Egypt. ${ }^{2}$ Alexandria STEM School, New Borg El Arab City, Alexandria, Egypt. ${ }^{3}$ Electronic Materials Research Department, Advanced Technology and New Materials Research Institute, City of Scientific Research and Technological Applications (SRTA-City), New Borg El Arab City, Alexandria, Egypt.

Received: 12 November 2021 Accepted: 10 January 2022

Published online: 03 February 2022

\section{References}

1. Shindhal T, Rakholiya P, Varjani S, Pandey A, Ngo HH, Guo W, Ng HY, Taherzadeh MJ (2021) A critical review on advances in the practices and perspectives for the treatment of dye industry wastewater. Bioengineered 12(1):70-87. https://doi.org/10.1080/21655979.2020.1863034

2. Nimako KO, Dwumfour A, Mensah K, Koshy P, Dankwah JR (2020) Calcination behaviour of nsuta rhodochrosite ore in the presence and absence of end-of-life high density polyethylene. Ghana Min J 20(2):22-35. https://doi.org/10.4314/ gm.v20i2.4

3. Baig MM, Gul IH (2021) Conversion of wheat husk to high surface area activated carbon for energy storage in highperformance supercapacitors. Biomass Bioenergy 144:105909 https://doi.org/10.1016/j.biombioe.2020.105909

4. Nasar A (2021) Utilization of tea wastes for the removal of toxic dyes from polluted water-a review. Biomass Convers Biorefinery:41-43 https://doi.org/10.1007/s13399-020-01205-y

5. Carvalho J, Araujo J, Castro F (2011) Alternative low-cost adsorbent for water and wastewater decontamination derived from eggshell waste: an overview. Waste Biomass Valorization 2(2):157-167. https://doi.org/10.1007/s12649-010-9058-y

6. Alslaibi TM, Abustan I, Ahmad MA, Foul AA (2013) A review: production of activated carbon from agricultural byproducts via conventional and microwave heating. J Chem Technol Biotechnol 88(7):1183-1190. https://doi.org/10.1 002/jctb.4028

7. Mensah K, Mahmoud H, Fujii M, Shokry H (2021) Upcycling of polystyrene waste plastics to high value carbon by thermal decomposition. Key Eng Mater 897:103-108. https://doi.org/10.4028/www.scientific.net/KEM.897.103

8. Asante BNP, Nimako KO, Mensah K et al (2020) Calcination behaviour of nsuta pyrolusite ore in the presence and absence of end-of-life polystyrene. Proc 6th UMaT Bienn Int Min Miner Conf:281-288 
9. Wang J, Nie P, Ding B, Dong S, Hao X, Dou H, Zhang X (2017) Biomass derived carbon for energy storage devices. J Mater Chem A 5(6):2411-2428. https://doi.org/10.1039/c6ta08742f

10. Mensah K, Mahmoud H, Fujii M, Shokry H (2022) Novel nano-ferromagnetic activated graphene adsorbent extracted from waste for dye decolonization. J Water Process Eng 45:102512 https://doi.org/10.1016/j.jwpe.2021.102512

11. Rhodes CJ (2018) Plastic pollution and potential solutions. Sci Prog 101(3):207-260. https://doi.org/10.3184/003685018X1 5294876706211

12. Mahanna H, Samy M (2020) Adsorption of Reactive Red 195 dye from industrial wastewater by dried soybean leaves modified with acetic acid. Desalin Water Treat 178:312-321 https://doi.org/10.5004/dwt.2020.24960

13. Sadeghi B, Marfavi Y, AliAkbari R et al (2021) Recent studies on recycled PET fibers: production and applications: a review. Mater Circ Econ 3 https://doi.org/10.1007/s42824-020-00014-y

14. Saratale RG, Sun Q, Munagapati VS, Saratale GD, Park J, Kim DS (2021) The use of eggshell membrane for the treatment of dye-containing wastewater: Batch, kinetics and reusability studies. Chemosphere 281:130777 httpse://doi.org/10.1016/ j.chemosphere.2021.130777

15. Thakur S, Singh S, Pal B (2021) Superior adsorptive removal of brilliant green and phenol red dyes mixture by CaO nanoparticles extracted from egg shells. J Nanostructure Chem https://doi.org/10.1007/s40097-021-00412-x

16. Chowdhury S, Chakraborty S, Das Saha P (2013) Removal of crystal violet from aqueous solution by adsorption onto eggshells: equilibrium, kinetics, thermodynamicsand artificial neural network modeling. Waste Biomass Valorization 4(3): 655-664. https://doi.org/10.1007/s12649-012-9139-1

17. Hassan TA, Rangari VK, Rana RK, Jeelani S (2013) Sonochemical effect on size reduction of CaCO3 nanoparticles derived from waste eggshells. Ultrason Sonochem 20(5):1308-1315. https://doi.org/10.1016/j.ultsonch.2013.01.016

18. Wang H, Gao B, Fang J, Ok YS, Xue Y, Yang K, Cao X (2018) Engineered biochar derived from eggshell-treated biomass for removal of aqueous lead. Ecol Eng 121:124-129 https://doi.org/10.1016/j.ecoleng.2017.06.029

19. Rajoriya S, Saharan VK, Pundir AS, Nigam M, Roy K (2021) Adsorption of methyl red dye from aqueous solution onto eggshell waste material: kinetics, isotherms and thermodynamic studies. Curr Res Green Sustain Chem 4:100180 https:// doi.org/10.1016/j.crgsc.2021.100180

20. Samy M, Alalm MG, Mossad M (2020) Utilization of iron sludge resulted from electro-coagulation in heterogeneous photo-fenton process. Water Pract Technol 15(4):1228-1237. https://doi.org/10.2166/wpt.2020.093

21. Adnyani NMLG, Febrida R, Karlina $\mathrm{E}$ et al (2020) Synthesis of nano calcium carbonate from natural $\mathrm{CaO}$ by $\mathrm{CO} 2$ fine bubbling method. AIP Conf Proc 2219:5-10 https://doi.org/10.1063/5.0003072

22. Sahoo TR, Prelot B (2020) Chapter 7 - Adsorption processes for the removal of contaminants from wastewater: the perspective role of nanomaterials and nanotechnology. Elsevier Inc.

23. Vaidya S, Ahmad T, Agarwal S, Ganguli AK (2007) Nanocrystalline oxalate/carbonate precursors of Ce and Zr and their decompositions to CeO2 and ZrO2 nanoparticles. J Am Ceram Soc 90(3):863-869. https://doi.org/10.1111/j.1551-2916.2 007.01484.x

24. El Essawy NA, Konsowa AH, Elnouby M, Farag HA (2017) A novel one-step synthesis for carbon-based nanomaterials from polyethylene terephthalate (PET) bottles waste. J Air Waste Manage Assoc 67(3):358-370. https://doi.org/10.1080/1 0962247.2016.1242517

25. Elkady M, Shokry H, El-Sharkawy A et al (2019) New insights into the activity of green supported nanoscale zero-valent iron composites for enhanced acid blue-25 dye synergistic decolorization from aqueous medium. J Mol Liq 294:111628 https://doi.org/10.1016/j.molliq.2019.111628

26. Elkady MF, Shokry Hassan H, El-Sayed EM (2015) Basic violet decolourization using alginate immobilized nanozirconium tungestovanadate matrix as cation exchanger. J Chem https://doi.org/10.1155/2015/385741 2015:1-10

27. Ganguli AK, Ahmed J, Vaidya S, Ahmad T (2007) Mimicking the biomineralization of aragonite (calcium carbonate) using reverse-micelles under ambient conditions. J Nanosci Nanotechnol 7(6):1760-1767. https://doi.org/10.1166/JNN.2007.711

28. Mehdizadeh P, Masjedi-Arani M, Amiri O, Salavati-Niasari M (2021) Rapid microwave fabrication of new nanocomposites based on Tb-Fe-O nanostructures for electrochemical hydrogen storage application. Fuel 304:121412 https://doi.org/10.1 016/j.fuel.2021.121412

29. Shokry Hassan H (2019) Role of preparation technique in the morphological structures of innovative nano-cation exchange. J Mater Res Technol 8(3):2854-2864. https://doi.org/10.1016/j.jmrt.2019.04.023

30. Elkady M, Hassan HS, Hashim A (2016) Immobilization of magnetic nanoparticles onto amine-modified nano-silica gel for copper ions remediation. Materials (Basel) 9:. https://doi.org/10.3390/ma9060460(6)

31. Koch C (2007) Nanostructured materials. In: Processing, properties and applications, 2nd edn. William Andrew

32. Stehr N (1988) Recent developments in stirred ball milling. Int J Miner Process 22(1-4):431-444. https://doi.org/10.1016/ 0301-7516(88)90077-4

33. Hiller R, Putterman S, Barber BP (1992) Spectrum of synchronous picosecond sonoluminescence. J Acoust Soc Am 92(4): 2454-2454. https://doi.org/10.1121/1.404513

34. Suslick KS (1994) The mechanochemical effects of ultrasound. Proc First Intl Conf Mechanochemistry Cambridge Intersci 1:43-49

35. Hassan TA, Rangari VK, Fallon V et al (2010) Mechanochemical and sonochemical synthesis of bio-based nanoparticles. Nanotechnol 2010 Bio Sensors Instruments Med Environ Energy - Tech Proc 2010 NSTI Nanotechnol Conf Expo NSTINanotech 3:278-281

36. Laca A, Laca A, Díaz M (2017) Eggshell waste as catalyst: a review. J Environ Manag 197:351-359 https://doi.org/10.1016/ j.jenvman.2017.03.088

37. Faridi H, Arabhosseini A (2018) Application of eggshell wastes as valuable and utilizable products: a review. Res Agric Eng 64(2):104-114. https://doi.org/10.17221/6/2017-RAE

38. Baláž M (2018) Ball milling of eggshell waste as a green and sustainable approach: a review. Adv Colloid Interf Sci 256: 256-275 https://doi.org/10.1016/j.cis.2018.04.001

39. Sathiparan N (2021) Utilization prospects of eggshell powder in sustainable construction material-a review. Constr Build Mater 293:123465 https://doi.org/10.1016/j.conbuildmat.2021.123465 
40. Pinchao-Pinchao YA, Ordoñez-Santos LE, Osorio-Mora O (2019) Evaluation of the effect of different factors on the ultrasound assisted extraction of phenolic compounds of the pea pod. DYNA 86(210):211-215. https://doi.org/doi.org/1 $0.15446 /$ dyna.v86n210.72880

41. Zhou G-T, Yao Q-Z, Fu S-Q, Guan Y-B (2010) Controlled crystallization of unstable vaterite with distinct morphologies and their polymorphic transition to stable calcite. Eur J Mineral 22(2):259-269. https://doi.org/10.1127/0935-1221/2009/ 0022-2008

42. Widyastuti S, Intan Ayu Kusuma P (2017) Synthesis and characterization of CaCO3 (calcite) nano particles from cockle shells (Anadara granosa Linn) by precipitation method. AIP Conf Proc 1855 https://doi.org/10.1063/1.4985488

43. Hrma PR (2008) Impact of particle size and agglomeration on settling of solids in continuous melters processing radioactive waste glass. J Nucl Mater. https://www.osti.gov/biblio/944856.

44. Febrida R, Cahyanto A, Herda E, Muthukanan V, Djustiana N, Faizal F, Panatarani C, Joni IM (2021) Synthesis and characterization of porous caco3 vaterite particles by simple solution method. Materials (Basel) 14(16) https://doi.org/1 $0.3390 /$ ma14164425

45. Thommes M, Kaneko K, Neimark AV, Olivier JP, Rodriguez-Reinoso F, Rouquerol J, Sing KSW (2015) Physisorption of gases, with special reference to the evaluation of surface area and pore size distribution (IUPAC Technical Report). Pure Appl Chem 87(9-10):1051-1069. https://doi.org/10.1515/pac-2014-1117

46. Ayawei N, Ebelegi AN, Wankasi D (2017) Modelling and interpretation of adsorption isotherms. J Chem. https://doi.org/1 $0.1155 / 2017 / 3039817$ 2017:1-11

47. Dane JH, Topp GC (2002) Methods of soil science society of America book series

48. Groen JC, Peffer LAA, Pérez-Ramírez J (2003) Pore size determination in modified micro- and mesoporous materials. Pitfalls and limitations in gas adsorption data analysis. Microporous Mesoporous Mater 60(1-3):1-17. https://doi.org/10.1 016/\$1387-1811(03)00339-1

Publisher's Note

Springer Nature remains neutral with regard to jurisdictional claims in published maps and institutional affiliations.

Submit your manuscript to a SpringerOpen ${ }^{\circ}$ journal and benefit from:

- Convenient online submission

- Rigorous peer review

Open access: articles freely available online

High visibility within the field

Retaining the copyright to your article

Submit your next manuscript at $>$ springeropen.com 